\title{
Development and usability of a decision support App for nurses to facilitate aging in place of people with dementia
}

Citation for published version (APA):

Thoma-Lurken, T., Lexis, M. A. S., Bleijlevens, M. H. C., \& Hamers, J. P. H. (2018). Development and usability of a decision support App for nurses to facilitate aging in place of people with dementia. Applied Nursing Research, 42, 35-44. https://doi.org/10.1016/j.apnr.2018.04.008

Document status and date:

Published: 01/08/2018

DOI:

10.1016/j.apnr.2018.04.008

Document Version:

Publisher's PDF, also known as Version of record

Document license:

Taverne

Please check the document version of this publication:

- A submitted manuscript is the version of the article upon submission and before peer-review. There can be important differences between the submitted version and the official published version of record.

People interested in the research are advised to contact the author for the final version of the publication, or visit the DOI to the publisher's website.

- The final author version and the galley proof are versions of the publication after peer review.

- The final published version features the final layout of the paper including the volume, issue and page numbers.

Link to publication

\footnotetext{
General rights rights.

- You may freely distribute the URL identifying the publication in the public portal. please follow below link for the End User Agreement:

www.umlib.nl/taverne-license

Take down policy

If you believe that this document breaches copyright please contact us at:

repository@maastrichtuniversity.nl

providing details and we will investigate your claim.
}

Copyright and moral rights for the publications made accessible in the public portal are retained by the authors and/or other copyright owners and it is a condition of accessing publications that users recognise and abide by the legal requirements associated with these

- Users may download and print one copy of any publication from the public portal for the purpose of private study or research.

- You may not further distribute the material or use it for any profit-making activity or commercial gain

If the publication is distributed under the terms of Article $25 \mathrm{fa}$ of the Dutch Copyright Act, indicated by the "Taverne" license above, 
Original article

\title{
Development and usability of a decision support App for nurses to facilitate aging in place of people with dementia
}

\author{
T. Thoma-Lürken ${ }^{\mathrm{a}, *}$, M.A.S. Lexis ${ }^{\mathrm{b}}$, M.H.C. Bleijlevens ${ }^{\mathrm{a}}$, J.P.H. Hamers ${ }^{\mathrm{a}}$ \\ ${ }^{\text {a }}$ Maastricht University, CAPHRI Care and Public Health Research Institute, Department of Health Services Research, Living Lab on Ageing and Long-term Care, \\ Duboisdomein 30, 6229 GT Maastricht, The Netherlands \\ ${ }^{\mathrm{b}}$ Zuyd University of Applied Sciences, Research Centre Technology in Care, Henri-Dunantstraat 2, 6419 PB Heerlen, The Netherlands
}

\section{A R T I C L E I N F O}

\section{Keywords:}

Decision support

Nurse

Dementia

Aging in place

\begin{abstract}
A B S T R A C T
Aim: The aim of this study was to develop a decision support tool for nurses to facilitate aging in place of people with dementia and to test its usability.

Background: Nurses play an important role in detecting practical problems preventing persons with dementia (PwD) from aging in place and advising them on possible solutions. These are complex and challenging tasks for nurses.

Methods: A mixed methods study was conducted. The content development of the App comprised a literature and internet search, and individual and group interviews with professionals $(n=8)$ and researchers $(n=5)$. The technical development was an iterative process in which usability was tested by the project team $(n=4)$, experts $(n=6)$, and end-users $(n=9)$, using heuristic evaluation, a think-aloud approach, and a questionnaire (PSSUQ). Results: The App contains a structured problem assessment for three problem domains—self-reliance, safety, and informal care-based on validated questionnaires and self-formulated questions. The problem assessment is linked to an overview of possible solutions for the problems detected. Three prototypes have been developed. The users of the third prototype were overall satisfied with the App as they scored on average 1.7 on the PSSUQ (range 1-7 and lower scores indicating higher satisfaction).

Conclusions: A user-friendly prototype of the decision support App is now available. Users indicated to be very willing to use to App in daily practice. However, besides further technical development, implementation of the App into practice requires evidence supporting its efficacy, feasibility and effectiveness.
\end{abstract}

\section{Introduction}

The incidence and prevalence of dementia worldwide is rapidly increasing as a result of the aging population (World Health Organization \& Alzheimer's Disease International, 2012). Currently, about 270,000 persons with dementia (PwD) live in the Netherlands, of whom around $70 \%$ are living at home supported by family members and professional care providers (Alzheimer Nederland, 2017). During the course of their disease, PwD become increasingly dependent on support from their network and over time often become susceptible to nursing home admission (Eaker, Vierkant, \& Mickel, 2002; Prince, Prina, \& Guerchet, 2013). However, PwD often prefer to continue to live a normal life in their own home for as long as possible (von Kutzleben, Schmid, Halek, Holle, \& Bartholomeyczik, 2012). In many Western countries, facilitating aging in place and delaying or even preventing nursing home admission is a common policy aim (Moïse,
Schwarzinger, \& Um, 2004). This is also the case in the Netherlands where, since long-term care reform in 2015, only people who need 24hour supervision are eligible for residential care (Maarse \& Jeurissen, 2016).

Despite both the wishes of the older persons themselves and policies focusing on aging in place, living at home can become extremely difficult for PwD. Dementia is characterized by ongoing cognitive and functional decline as well as behavioral changes, causing increased problems in daily functioning and dependency (MacNeil Vroomen et al., 2015). As the dementia process proceeds, people often experience problems in performing instrumental activities of daily living (IADL) (e.g. handling finances or preparing hot drinks) (Giebel, Challis, \& Montaldi, 2015) or more basic activities of daily living (ADL) (e.g. going to the toilet or eating) (Risco et al., 2015). A recent study of practical problems preventing PwD from living at home has shown that problems in three particular domains seem to be the most striking.

\footnotetext{
* Corresponding author.

E-mail addresses: t.thoma@maastrichtuniversity.nl (T. Thoma-Lürken), monique.lexis@zuyd.nl (M.A.S. Lexis), m.bleijlevens@maastrichtuniversity.nl (M.H.C. Bleijlevens), jph.hamers@maastrichtuniversity.nl (J.P.H. Hamers).
} 
These domains are decreased self-reliance (e.g. inability to conduct ADL activities or to plan and structure a day), safety-related problems (e.g. improper use of electronic devices, wandering, or fall injuries), and informal care/network-related problems (e.g. high burden or absence of informal caregivers) (Thoma-Lürken, Bleijlevens, Lexis, \& Hamers, 2018).

To facilitate aging in place of PwD the focus should be on the early detection of practical problems and the introduction of possible solutions. Various technological solutions (e.g. lifestyle monitoring, screento-screen care, GPS systems, and internet-based interventions) as well as social solutions (e.g. respite care facilities, day care at green-care farms, and case management) to support PwD and their informal caregivers are currently available (Boots, de Vugt, van Knippenberg, Kempen, \& Verhey, 2014; Gibson et al., 2014; Schols \& van der Schriekvan Meel, 2006; Thoma-Lürken, Bleijlevens, Lexis, Hamers, \& de Witte, 2015). Nevertheless, PwD and their informal caregivers might not be aware of all these options (van der Roest et al., 2009; Wolfs, de Vugt, Verkaaik, Verkade, \& Verhey, 2010).

Professionals in community-based dementia care play an important role in assessing practical problems and searching for possible care and treatment options for PwD and their caregiver(s) in order to deal with the problems that PwD experience in daily life (Wolfs et al., 2010). In the Netherlands, district nurses and case managers often fulfill this coaching and coordinating role (de Bont, van Haaren, Rosendal, \& Wijboldus, 2012; MacNeil Vroomen et al., 2015). Professionals are expected to have insight into the needs, problems, and preferences of their clients and their informal caregivers, which may change over time. They should be able to advise them continually on possible solutions (e.g. professional care options, assistive technology, information sources, or informal caregiver support) to deal with the practical problems identified and to develop an individual action and intervention plan to facilitate aging in place (Alzheimer Nederland \& Vilans, 2013; de Putter, Francke, de Veer, \& Rademakers, 2014). District nurses and case managers are thus faced with complex diagnostic and advisory tasks, as these professionals need to have detailed insight into the constantly changing individual situation of a client and be aware of possible and evolving solutions.

There are various tools (e.g. questionnaires, checklists, and assessment forms) that professionals can use to gain insight into the different aspects of problems that PwD and their informal caregivers might experience. In the Dutch guidelines for community-based dementia care it is stated that individual need for care should be assessed according to the 'state of the art' (Alzheimer Nederland \& Vilans, 2013). However, the guidelines provide freedom for professionals to choose between various tools. From research it is known that besides the explicit use of tools, nurses also rely on their intuition and experience when making judgments and decisions (Thompson, Aitken, Doran, \& Dowding, 2013). Consequently, problem assessment and advice on possible solutions to these problems may depend on the knowledge and experience of the individual professional.

A decision support tool that combines a structured problem assessment with an overview of possible solutions could assist case managers and district nurses in their coaching and coordinating role. In these times of electronic client files and the use of tablet-computers by nurses and case managers, a computerized decision support tool for these professionals could be easily integrated into their work process. Computerized decision support for nurses is defined broadly by Dunn Lopez et al. (2017, p. 441) as "providing clinicians (nurses) with computer-generated clinical knowledge and patient-related information which is intelligently filtered and presented at appropriate times to enhance patient care."

As facilitating aging in place is the central aim of community-based dementia care in the Netherlands, a decision support tool for district nurses and case managers should focus on the three most important practical problems preventing PwD from living at home, as described above (decreased self-reliance, safety-related problems, and informal care/network-related problems), and provide solutions to these problems. To develop a successful tool that will be used in daily practice, it is essential to involve end-users from the start of the process to make sure that the tool is adapted to their needs (Jaspers, 2009). Therefore, a stepwise, user-centered development process was considered the most appropriate method for designing a decision support tool for professionals with a coaching and coordinating role in community-based dementia care.

The aim of this study was to develop a decision support tool for district nurses and case managers to facilitate aging in place of people with dementia and to test its usability. The tool aims to support the process of problem assessment and provide solutions for problems within the domains of decreased self-reliance, safety-related problems, and informal care/social network-related problems.

\section{Materials and methods}

A mixed-methods study was conducted to develop, in close collaboration with potential end-users (district nurses and case managers), a decision support tool in the form of an application (App) to be installed on a tablet PC. Fig. 1 shows that the stepwise, user-centered development process was divided into two phases: content development and technical development. For the content development a literature and internet search, and individual and group interviews, were conducted. The technical development took the form of an iterative process of prototype development and usability testing using a think-aloud approach, heuristic evaluation, and a questionnaire to assess level of usability.

\subsection{Research setting and subjects}

The study was conducted in the region of Limburg in the south of the Netherlands. Participants were recruited from four, long-term care organizations that provide home care and participate in the Living-Lab in Ageing and Long-Term Care, South Limburg (Verbeek, Zwakhalen, Schols, \& Hamers, 2013), the Centre of Excellence for Innovative Care and Technology (Centre of Expertise for Innovative Care and Technology, 2015), or the regional care network for dementia care (Hulp bij Dementie, 2016).

The tool was developed for professionals with a coordinating and coaching function in community-based dementia care (e.g. case managers and district nurses). In the Netherlands a case management program has been introduced into community-based dementia care over the past decades (MacNeil Vroomen et al., 2012). Case management is defined as "a collaborative process which: assesses, plans, implements, co-ordinates, monitors and evaluates the options and services required to meet an individual's health, social care, educational and employment needs, using communication and available resources to promote quality cost effective outcomes" (Case Management Society UK, 2017). District nursing can be described as follows: "Home nursing care (wijkverpleging) is provided by district nurses (wijkverpleegkundigen). District nurses assess the needs of their clients and coordinate the care between client, informal carers, GPs, other healthcare professionals and social care professionals involved in the care for the client. They provide nursing care and personal care, such as dressing and bathing" (Kroneman et al., 2016, p. 143).

We purposely selected three groups of participants for the content and technical development of the App. These groups were: first, experienced professionals (district nurses or case managers) working in community-based care, as potential end-users; second, researchers with particular knowledge in the field of gerontology or assistive technology; and third, experts in the field of application development in health care. Table 1 provides an overview of the distribution of participants in both development phases. 


\section{Development process of decision support app}

The app focusses on three problem domains based on the results of a prior study:

- Self-reliance

- Safety-related problems

- Informal care/network-related problems

\section{Content development}

1. Problem assessment part

Searching and selecting assessment tools and development of additional questions

to detect problems within the three domains.

Methods used:

Literature and internet search, prior focus group study, interviews (individual and group)

3. Combining problem assessment part with the overview of possible solutions part into an overall flowchart

\section{Technical development}

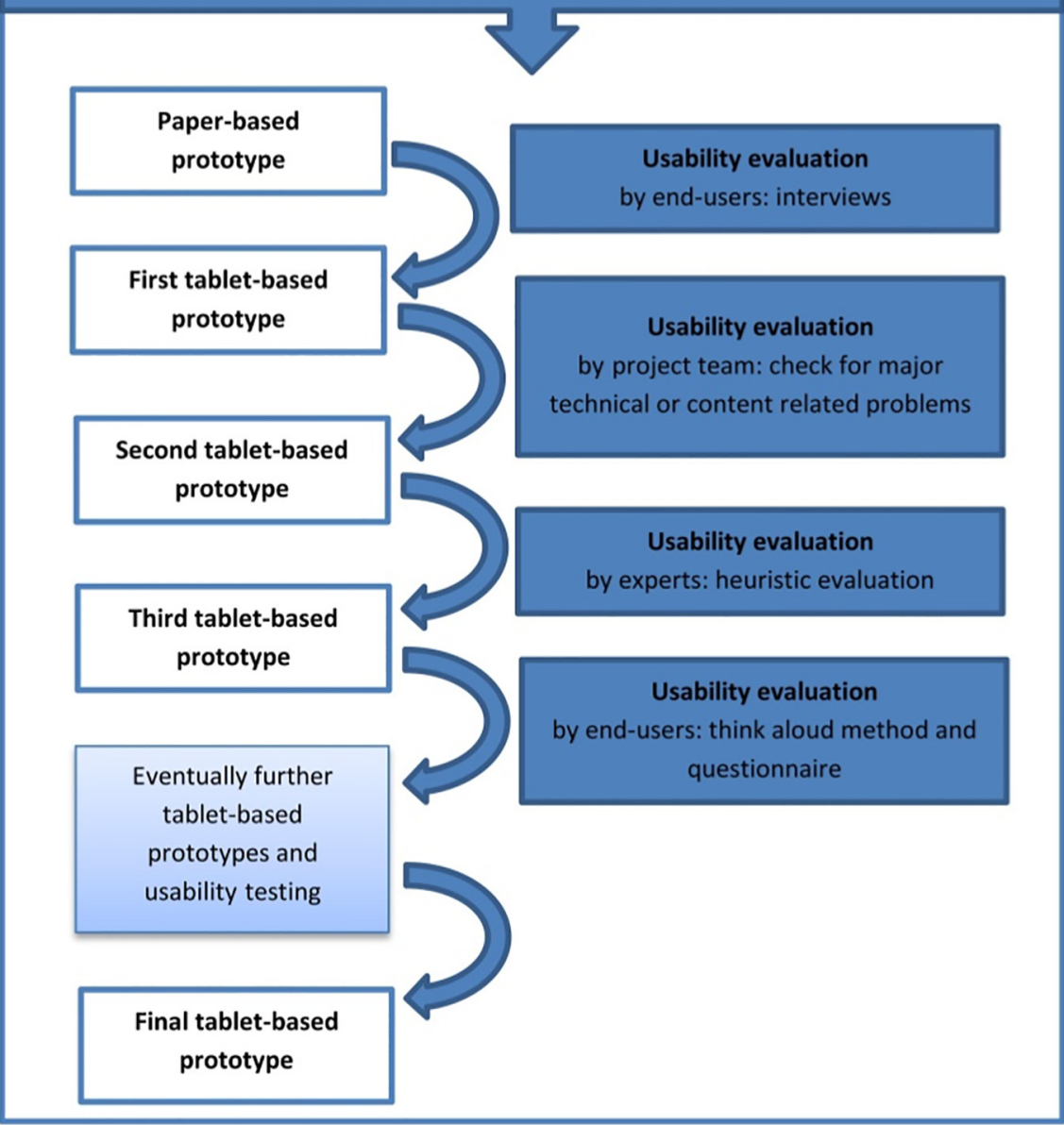

Fig. 1. Development process of the decision support tool. 
Table 1

Overview of participants in the development process.

\begin{tabular}{lll}
\hline Phase & Type participants & $\mathrm{N}$ \\
\hline 1. Content development & Case managers & 6 \\
& District nurses & 2 \\
& Researchers & 5 \\
2. Technical development and usability & Case managers & 5 \\
evaluation & District nurses & 4 \\
& App development experts & 5 \\
& Project team (researchers) & 4 \\
\hline
\end{tabular}

\subsection{Data collection and procedure}

\subsubsection{Content development}

The content development consisted of three steps. In the first, the problem assessment part of the tool was developed. To select suitable and widely used assessment tools in the domains of decreased self-reliance, safety-related problems, and informal care related problems we asked professionals working in community-based dementia care ( $n=16$ ), during focus group interviews in a prior study (Thoma-Lürken et al., 2018), to give an overview of the tools they use in daily practice to assess the problems faced by their clients that could prevent them from living at home. In addition, an internet search to identify current guidelines for community-based dementia care in the Netherlands was conducted, in order to ascertain whether those guidelines gave suggestions for assessment tools. A literature search was also conducted, in PubMed, Google Scholar and Google, to identify available (evidencebased) tools for problem assessment in at least one of the three problem domains. The search terms used were related to the problem domains of self-reliance (ADL, IADL, daily activities, day structure, day/night rhythm), safety (safety, risk assessment), and informal care/network (informal care, network, burden). From the resulting overview of possible instruments, the project team made an initial selection of instruments to be included in the App. For this selection, the following criteria for the tool were kept in mind: it is currently used by professionals; it is feasible to use in daily practice (e.g. with regard to time needed to complete the assessment, availability of the tool in the Dutch language); and, it has been validated. Additional questions were developed by the project team for problems that had been identified as being important in preventing PwD from living at home in a prior study (Thoma-Lürken et al., 2018), but were not covered by existing tools. The project team also developed questions to gain deeper insight into the problems and to assess whether new solutions were needed or suitable solutions were already in place. To develop an algorithm for the App, the questionnaires and self-developed questions were integrated into flowcharts describing the process from problem assessment to problem statement. The initial flowcharts were evaluated in two group interviews (first $n=5$, second $n=2$ ) and one individual interview $(n=1)$ with case managers and district nurses. The flowcharts were then adapted according to the feedback from the interviews. The updated versions of the flowcharts were then evaluated in individual interviews with district nurses and case managers $(n=3)$. In addition, the flowcharts were discussed with researchers who are experts in gerontology $(n=3)$. The aim of these interviews was to evaluate the selected questionnaires and to assess the face-validity of the newly developed questions. Based on the feedback of professionals and researchers, the flowcharts were again adapted.

In the second step, an overview was compiled of possible technological and non-technological solutions for each problem that could be detected through the problem assessment in the domains of decreased self-reliance, safety-related problems, and informal care and network related problems. For this purpose, an internet search was conducted on guidelines for community-based dementia care in the Netherlands, national and international databases for assistive technology, and dementia-related websites of, e.g. national patient organizations, national research institutes, centers of excellence). Moreover, two experts in assistive technology and one expert in dementia interventions were interviewed.

Finally, in the third step both parts, the problem assessment and the overview of possible solutions, were combined in one final flowchart. This final flowchart served as the basis for the development of a paperbased prototype of the App.

\subsubsection{Technical development and usability evaluation}

To eliminate major usability issues from the start, the technical development started with a paper-based prototype. This graphical representation of the actual App was evaluated in interviews with district nurses and case managers $(n=6)$ on its usability in terms of intuitive use, structure, and layout. The feedback provided by the participants was used to develop the first prototype of the App. Subsequent prototypes of the actual App were developed iteratively in conjunction with an engineering team. Each prototype was evaluated with regard to its usability. The feedback from each usability evaluation served as input for the improvement of the next prototype.

The first prototype was evaluated by researchers from the project team $(n=4)$. They checked whether the flowcharts were correctly translated into the digital version of the App and whether the App was technically stable.

The second prototype was evaluated by experts in the field of App development in health care $(n=5)$, using heuristic evaluation based on the 10 Usability Heuristics of Nielsen (Nielsen, 1994). Individual interviews with the experts were organized. First, the experts got a few minutes to explore the App on their own. Then, they were asked to conduct thirteen predefined tasks with the App (e.g. logging on, conducting a problem assessment in one of the three domains, consulting the overview of possible solutions). While completing these tasks they were asked to provide suggestions for further improving the App's usability. Their comments were summarized on screen shots. After completion of the tasks the experts were asked to fill in a questionnaire in which they were requested to judge the App against the 10 Usability Heuristics of Nielsen (Nielsen, 1994) (e.g. visibility of system status, language use, error prevention, esthetic, and minimalistic design), with scores ranging from 1 (bad) to 7 (good). For each item mean scores were calculated in order to detect major usability flaws. A mean score of 4 or lower was regarded as a violation of the heuristic (van der Weegen, Verwey, Tange, Spreeuwenberg, \& de Witte, 2014). In addition, the participants were asked to rate the importance of each individual principle on a scale of 1 (not important) to 7 (very important). Finally, the researcher who conducted the interviews discussed the feedback and the scores from the heuristic evaluation with the experts.

The third prototype was evaluated by potential end-users (case managers and district nurses) $(n=9)$, using a think-aloud approach (Jaspers, 2009) and a Dutch version of the Post-Study System Usability Questionnaire (PSSUQ). The PSSUQ is a 19-item questionnaire rated on a 7-point Likert scale (answers ranging from strongly disagree to strongly agree), which is used to assess users' perceived satisfaction with computer systems (Lewis, 1995; van der Weegen et al., 2014). The PSSUQ consists of one overall satisfaction scale (OVERALL: Items 1 through 19) and three subscales: system usefulness (SYSUSE: Items 1 through 8), information quality (INFOQUAL: Items 9 through 15), and interface quality (INTERQUAL: Items 16 through 18) (Lewis, 1995). For all scales the rating range was between 1 and 7 ; the lower the score, the higher the satisfaction. After the usability evaluation of the third prototype, the feedback was adopted. On the basis of positive feedback from the users, the project team decided that no further prototypes were needed and that the efficacy of the latest version could be tested in a next phase.

For all participants data on age, gender, profession and educational level were gathered. 


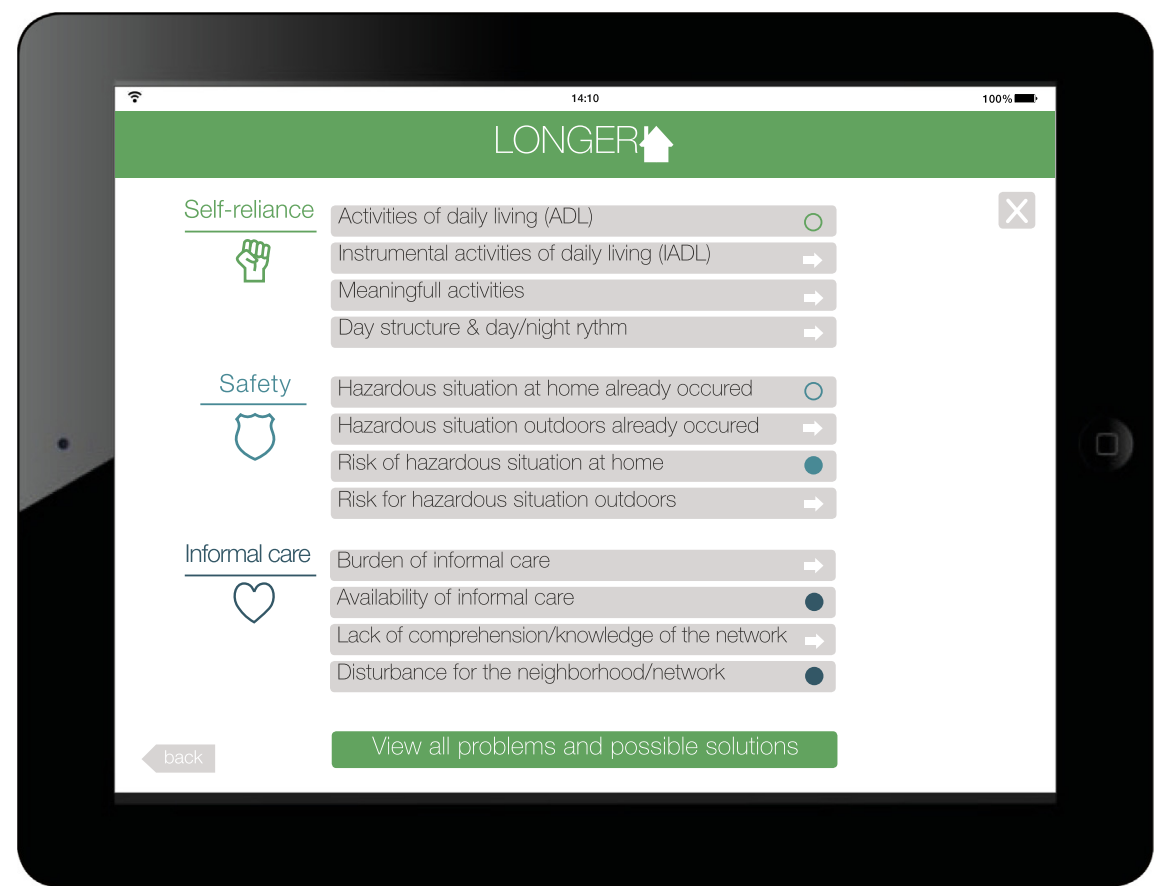

Fig. 2. The Longer at home App.

\subsection{Data analysis}

\subsubsection{Content development}

The feedback provided during the interviews was summarized and clustered by topic, e.g. self-reliance, safety, informal care, overall feedback. The feedback was then discussed by the project team in order to evaluate whether the suggested improvements required immediate adoption in order to achieve the actual goal: i.e. to develop an App, focusing on three major problem domains that could be tested in a laboratory setting before possible implementation in practice. Hence, the feedback was categorized according to whether it should be adopted immediately, kept for possible adoption at a later stage, or not adopted at all.

\subsubsection{Technical development}

Feedback regarding the usability of the different prototypes was written on screen shots. At the end of the process, the feedback on each screen was summarized and subsequently discussed by the project team. Again, the team evaluated whether the improvements required immediate adoption in order to achieve the goal of developing an App that could be tested in a laboratory setting. Another aspect the team considered was whether the suggested technical adjustments were possible within the financial constraints of the project. On this basis the feedback was then categorized according to whether it should be adopted immediately, kept for possible adaptations at a later stage, or not adopted at all.

The quantitative data from the heuristic evaluation and the PSSUQ were analyzed through descriptive analyses (means and standard deviations) using SPSS software (IBM SPSS statistics 23).

\subsection{Ethical considerations}

No ethics approval was needed for this study according to Dutch Law (Central Committee on Research Involving Human Subjects, n.d.). The participation was strictly voluntary for all participants. Furthermore, the CEO's of the participating organizations gave consent to recruit employees form their organizations.

\section{Results}

\subsection{Content development}

Overall, eight different professionals working in community-based dementia care either as case managers or district nurses participated in the content development phase. The majority were female $(n=7)$. The mean age of participants was 41 years, ranging from 23 and 53 years. In addition, five different researchers participated in interviews, three with a background in gerontology and two in assistive technology. The researchers' mean age was 45 , ranging from 32 and 58 years. The majority were female $(n=4)$, and all had at least a Master's $(n=2)$ or PhD $(n=3)$ degree.

\subsection{Assessment tools}

Different tools were identified that could be used by professionals to assess specific elements of the situation of people with dementia and their informal caregivers. Appendix 1 provides an overview of the identified tools in the three problem domains decreased self-reliance, safety-related problems and informal care/network-related problems.

\subsection{Content of the decision support tool}

The final App consists of two parts: a stepwise problem assessment and an overview of possible solutions in three problem domains-decreased self-reliance, safety-related problems, and informal care/network-related problems. Both parts are interrelated in the sense that the App provides tailored suggestions for possible solutions to the problems detected during assessment.

Based on the results of a prior study (Thoma-Lürken et al., 2018) and the feedback provided by participants in the current study, all three problem domains were dived into four subcategories. Decreased selfreliance was subdivided into: Activities of Daily Living (ADL), Instrumental Activities of Daily Living (IADL), meaningful activities (leisure time and work), and day structure \& day/night rhythm. Safety-related problems were subdivided into: hazardous situations at home that have already occurred, hazardous situations outdoors that have already occurred, the risk of hazardous situations at home, and the risk of 


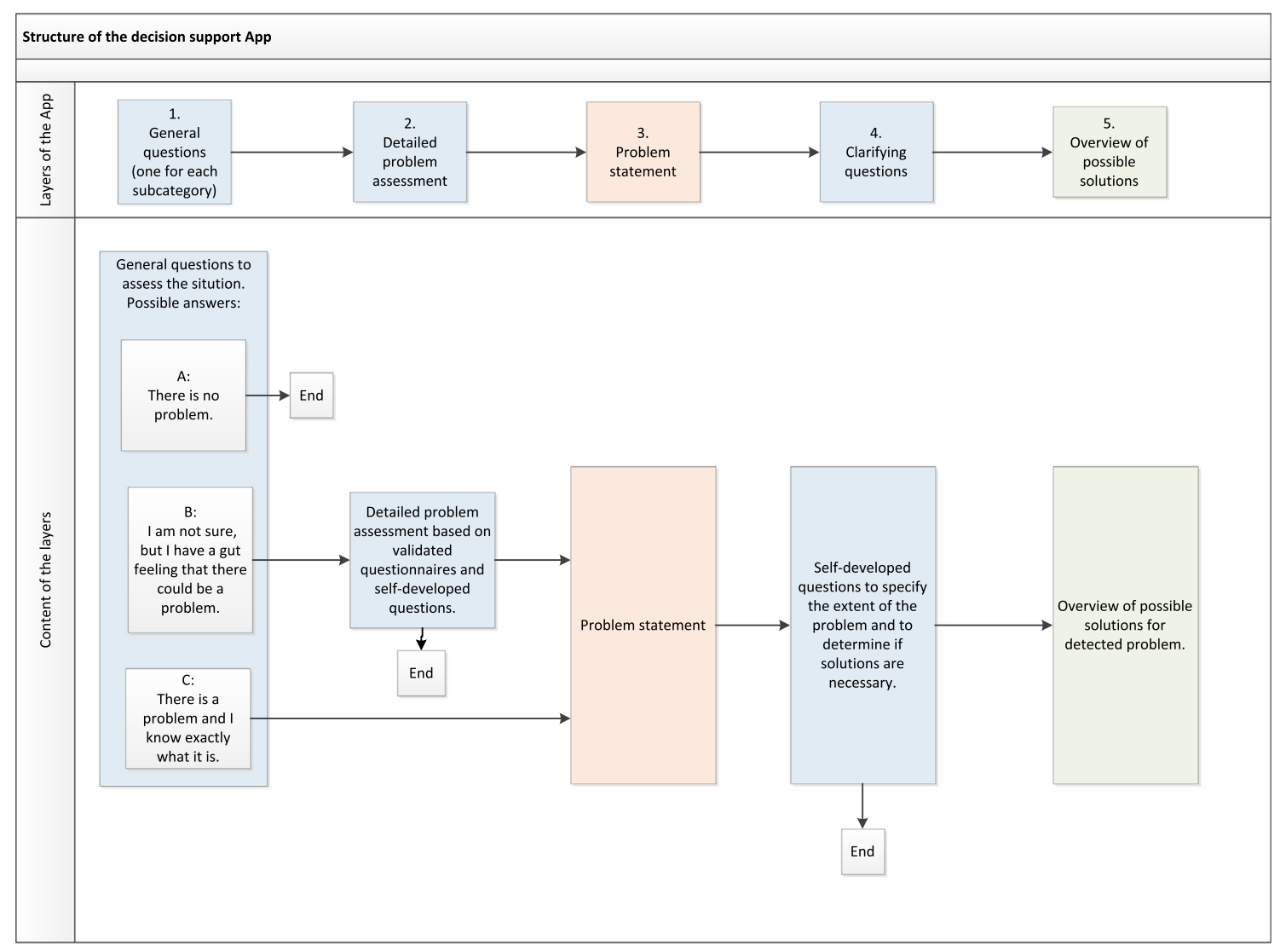

Fig. 3. Layers of the App.

hazardous situations outdoors. Informal care/network related problems were subdivided into: burden of informal care, availability of informal care, lack of comprehension/knowledge of the network, and disruption of the neighborhood and/or the person's network (Fig. 2).

The final App contains five different layers (Fig. 3): three different layers of questions, a problem statement, and an overview of possible solutions. The problem assessment for the three domains contains three layers of questions. The first layer contains general questions, one for each of the four subcategories to assess whether there is a problem in that subcategory. For example, for the subcategory activities of daily living (ADL) the general question is as follows: "Is the person with dementia able to conduct all basic ADL activities with the support he/ she receives at the moment?" A sample question for the subcategory caregiver burden is: "Are there any signs that the caregiver perceives a high burden of care responsibility?" The general questions have three possible answers: A: There is no problem; B: I'm not sure, but I have a gut feeling that there could be a problem; and, C: There is a problem and I know exactly what it is. If option A is chosen, the problem assessment for that specific category ends and one may decide to assess another category. If option B is chosen, the user is directed to the second layer of questions. This layer contains questions to assess the situation in more detail (questions to conduct a detailed problem assessment). These questions are posed in case the 'I'm not sure' option was chosen for one or more of the general questions, in order to guide the professional through a structured problem assessment. The detailed problem assessment was partly based on validated questionnaires. Based on the criteria of current use in practice, feasibility and psychometric properties the following tools were selected: the Dutch version of the Barthel index for ADL (de Haan et al., 1993); a Dutch translation of the Lawton and Brody IADL questionnaire for IADL (Lawton \& Brody, 1969); the Dutch version of the Self-perceived Pressure from Informal Care (SPPIC) to assess caregiver burden (Pot, Deeg, van Dyck, \& Jonker, 1998); a translation of the items of the Home
Safety Inventory to assess hazardous situations (Lach, Reed, Smith, \& Carr, 1995) and partly on self-formulated questions in case no validated questionnaires were available. Based on the results of the detailed problem assessment, a problem statement is generated automatically including an overview of the detected problems. In case no problem is detected, the assessment of the subcategory ends. If the user chooses option $\mathrm{C}$ in the first layer, indicating that they know exactly what the problem(s) is or are, they are immediately directed to the problem statement. In this case, the professional defines the problem based on prior knowledge by selecting a problem from a pre-defined list. The problem statement is followed by the third layer of questions. This layer contains questions intended to gain more insight into the problems (clarifying questions): These questions can be used to assess whether possible problems are already being sufficiently tackled or if new solutions are needed. For example, when a problem with a basic ADL activity such as going to the toilet is detected, a clarifying question would be: "Does the inability to go to the toilet hinder the daily functioning of the person?" If the answer is yes, the next question is "Does the person receive any support with toileting or is there any other compensatory solution in use?" If the answer is yes, the last question asks: "Is/are the delivered care or support/solutions sufficient?" If the answer is no, the user will be guided to an overview of possible solutions to this specific problem. Finally, the problem assessment results in a list of detected problems in the three problem domains. All the problems are linked to an overview of possible solutions to deal with them. The solutions are based on guidelines for community-based dementia care in the Netherlands, national and international databases for assistive technology, and dementia-related websites of, e.g. national patient organizations, national research institutes, centers of excellence, and information provided by researchers as experts in the field. The solutions vary between relatively simple suggestions/tips for information (e.g. information websites, guidelines) and supportive aids and devices (e.g. drug dispensers with a reminder function, walking 
frames), to more complex, technological solutions, such as GPS devices, lifestyle monitoring systems, or screen-to-screen care. The overview contains a broad spectrum of solutions and it is up to the user to decide which might be suitable and might then be discussed with, and/or recommended to, the client, or his/her family or social network.

\subsection{Technical development and usability evaluation}

\subsubsection{Paper-based prototype}

The paper-based prototype of the App was evaluated by six potential end-users (five case.

managers, one district nurse). All were women, with a mean age of 39 years (range 23 and 52 years). Overall, the participants were positive about the intuitive use, readability, and layout of the paper-based prototype. They appreciated the clear and minimalistic design, and indicated that they were keen to use the App in daily practice. Examples of suggestions for improvement, which were subsequently adopted, included: 1.) adding an overview page showing all three problem domains and sub-themes at a glance, including an opportunity to request more information on the exact content of the problem domains; 2.) adding the opportunity to temporarily skip questions when answers are not immediately available; 3.) adding more information on individual items and sum scores of validated questionnaires, to be better able to interpret the results of the assessment; and, 4.) changing the layout of the App from portrait to landscape, as the professionals were used to using a tablet PC in landscape format.

\subsubsection{Evaluation by the project team of the first tablet-based prototype of the App}

The first prototype is an App that runs on an iPad2 with internet connection. Four project team members evaluated the first tablet-based prototype of the App to detect any major usability issues that needed to be eliminated immediately. This evaluation led to the detection of errors in the sequence of questions, missing functions (e.g. the ability to search for more information, links to external websites), and the technical stability of the App. All identified problems were forwarded to the engineering team, who resolved the problems where possible.

\subsubsection{Evaluation by experts of the second tablet-based prototype of the App}

Five experts in the field of App development in health care participated in a heuristic evaluation. Two experts were men and three women, with a mean age of 33 years (ranging from 28 to 46 years). The experts had different educational backgrounds (e.g. health sciences, occupational therapy, informatics, and psychology). The evaluation of Nielsen's heuristics (Nielsen, 1994) indicated no major flaws (defined as scores of 4 or lower) in the system, as all items scored on average 4.8 or higher (Table 2). The experts indicated that they would have liked information showing their progress during the problem assessment process. This issue was resolved by adding icons to the main screen that
Table 3

Results of the post study system usability questionnaire.

\begin{tabular}{ll}
\hline Scores on PSSUQ & $\begin{array}{l}\text { Mean scores (SD); } \\
\text { Range } 1-7 \\
\text { Lower scores indicate better usability }\end{array}$ \\
\hline Overall satisfaction & $1.7(0.5)$ \\
System usefulness & $1.8(0.7)$ \\
Information quality & $1.6(0.4)$ \\
Interface quality & $1.9(0.9)$ \\
\hline
\end{tabular}

visually depicted the status of the problem assessment. With regard to the flexibility and efficiency of using the App, the experts said that the App lacked a page giving an overview of all the problems and solutions. This option was added to the third and final prototype.

3.4.4. Evaluation by end-users of the third tablet-based prototype of the App Nine potential end-users participated in the evaluation sessions (five case managers and four district nurses). All the participants were women, mean age 41 years (ranging from 23 to 60 years). The results of the PSSUQ showed that the participants were satisfied with the usability of the App (Table 3). Problems that were detected mainly related to the technical stability of the App, which was subsequently adapted in the final version.

\section{Discussion}

This mixed-methods study resulted in the development of a usable decision support App. The App contains both a structured problem assessment and an overview of possible solutions for problems in the domains of decreased self-reliance, safety-related problems, and informal care/network-related problems. The problem assessment contains three layers of questions, culminating in a problem statement that is linked to an overview of possible solutions for each problem detected. The usability of all the prototypes was evaluated positively, with the feedback from each round serving as input for the development of the next prototype.

A strength of this study is that throughout the development process the principles of user-centered design were respected (Gulliksen et al., 2003). The involvement of nurses and case managers in each phase of the development process should increase the chance of the decision support App's implementation in practice being successful, given that involvement of users in the development of an innovation is a facilitating factor for implementation (Grol \& Wensing, 2013). Other facilitating factors for successful implementation of innovations are compatibility, which means that the innovation fits existing norms and values, and adaptably, which means that the innovation can be adapted to the needs of the target group (Grol \& Wensing, 2013). By involving users in all phases of the development, it can be assumed that the final

Table 2

Results of the heuristic evaluation.

\begin{tabular}{|c|c|c|}
\hline Heuristic principles & $\begin{array}{l}\text { Mean scores (SD) } \\
\text { Rating (range 1-7); } \\
1 \text { (bad)-7 (good) }\end{array}$ & $\begin{array}{l}\text { Mean scores (SD) importance of the principle (range 1-7) } \\
1 \text { (not important)-7 (very important) }\end{array}$ \\
\hline 1. Visibility of system status & $4.8(1.6)(N=5)$ & $5.2(0.8)(\mathrm{N}=5)$ \\
\hline 2. Match between system and the real world & $6.0(1.0)(N=5)$ & $6.6(0.9)(\mathrm{N}=5)$ \\
\hline 3. User control and freedom & $5.6(1.7)(N=5)$ & $6.2(0.4)(\mathrm{N}=5)$ \\
\hline 4. Consistency and standards & $6.0(1.2)(N=5)$ & $6.4(0.5)(\mathrm{N}=5)$ \\
\hline 5. Error prevention & $6.7(0.6)\left(\mathrm{N}=3^{\mathrm{a}}\right)$ & $6.4(0.5)(N=5)$ \\
\hline 6. Recognition rather than recall & $6.4(0.9)(\mathrm{N}=5)$ & $6.0(1.4)(\mathrm{N}=5)$ \\
\hline 7. Flexibility and efficiency of use & $5.4(1.5)(\mathrm{N}=5)$ & $5.8(0.8)(\mathrm{N}=5)$ \\
\hline 8. Esthetic and minimalist design & $6.0(1.0)(\mathrm{N}=5)$ & $5.4(0.5)(\mathrm{N}=5)$ \\
\hline 9. Help users recognize, diagnose, and recover from errors & $6.0(0.0)\left(\mathrm{N}=2^{\mathrm{a}}\right)$ & $6.4(0.5)(\mathrm{N}=5)$ \\
\hline 10. Help and documentation & $5.8(1.0)\left(\mathrm{N}=4^{*}\right)$ & $5.2(1.3)(\mathrm{N}=5)$ \\
\hline
\end{tabular}

a Missings: participants scored not applicable. 
App is in line with the norms and values of nurses and case managers and is adapted to their needs. A review by Kawamoto, Houlihan, Balas, and Lobach (2005) concluded that four features of decision support tools for professionals can increase the change of improvements in clinical practice. These are: integrating decision support in the workflow, providing both assessment and recommendations, providing support at the time when the decision is taken, and computer-based decision support. This decision support App for case managers and district nurses meets all these requirements. It has been developed in close collaboration with end-users, which means that it is adapted to their needs and fits into their workflow (Shah, Robinson, \& AlShawi, 2009). Professionals indicated that the tool could be used in various ways: for example, in direct contact with the client or informal caregiver in order to assess the situation or discuss possible solutions, or prior to a home visit for preparation purposes or afterwards as a checkup.

\subsection{Limitations and challenges}

To identify available tools for problem assessment in the three domains, decreased self-reliance, safety-related problems, and informal care and network-related problems, a literature search was conducted. It was beyond the scope of this study to conduct various systematic reviews over several databases with a comprehensive set of search terms and strict selection criteria. Consequently, there is a chance that not all available tools were screened. However, the App is designed to be sufficiently flexible that where new, more suitable tools are identified they can be integrated at a later stage.

With regard to the overview of possible solutions, while the App does not provide information about the scientific evidence behind the individual solutions it is based on clinical knowledge and expert opinion. However, information about the scientific underpinning of solutions might be valuable information for professionals who are expected to make evidence-based decisions. Adding information concerning the effectiveness and suitability of the interventions, and keeping the overview of possible solutions up to date could be the greatest challenge when it comes to implementing the App in practice. Further research would be needed to screen, evaluate, and summarize available (scientific) literature on possible solutions.

To evaluate the usability of the App, the Dutch version of the PSSUQ was used. No information on its psychometric properties is available as yet. However, the main goal was to detect usability flaws in order to further improve the App rather than to compare its scores with norms; the latter is also not recommended by the developers of the PSSUQ (Lewis, 2014).

\subsection{Implications for practice and directions for further research}

The App aims to help professionals to deal with complex diagnostic and advisory tasks. It may also increase their awareness of problems that prevent PwD from living at home and aims to support them in exploring possible solutions to those problems. However, in its current version the App is only to be used for research purposes. To actually implement the App in daily practice, additional development steps need to be taken. For example, to ensure the security of client data the App needs to be adapted according to current guidelines. Moreover, the overview of possible solutions should be updated constantly as new solutions become available. An example of an adaptation that was considered desirable by the participating professionals was the option of extraction of data from the App and linkage to the electronic patient file. Moreover, participants felt that it would be valuable if the App contained additional to general solutions also local solutions available in the specific area in which they worked. Due to available time and financial constraints it was not possible to carry out all the suggested improvements of the App immediately.

Besides further technical development, implementation of the App into practice also requires evidence supporting its efficacy, feasibility and effectiveness.

\section{Conclusions}

A usable decision support App for nurses and case managers working in community-based dementia care, which guides the user though a stepwise problem assessment and provides an overview of possible solutions for the problems detected, is available now. However, additional development and research is needed before actual implementation in practice should be considered.

\section{Funding}

This work was supported by the Province of Limburg, The Netherlands (grant no. 2013/15434).

\section{Conflict of interest}

None.

\section{Acknowledgment}

IDEE/MEMIC-Maastricht University, the Netherlands were involved in the technical development of the application.

The authors wish to thank the participants for their valuable contribution to the development and testing of the decision support tool. Moreover, we would like to thank Nadine Spierts who participated in data collection.

\section{Appendix 1. Overview of assessment tools}

\begin{tabular}{|c|c|c|}
\hline $\begin{array}{l}\text { Barthel index (Dutch translation) (de Haan } \\
\text { et al., 1993) }\end{array}$ & Home safety inventory (Lach et al., 1995) & $\begin{array}{l}\text { Self-perceived pressure from informal care } \\
\text { (SPPIC) (Pot et al., 1998) }\end{array}$ \\
\hline GARS (Kempen \& Suurmeijer, 1990) & $\begin{array}{l}\text { HEAP home environmental assessment protocol } \\
\text { (Gitlin et al., 2002) }\end{array}$ & $\begin{array}{l}\text { Caregiver strain index (CSI) (Robinson, } \\
\text { 1983) }\end{array}$ \\
\hline $\begin{array}{l}\text { Self-Sufficiency Matrix (SSM-D) (Fassaert } \\
\text { et al., 2014) }\end{array}$ & $\begin{array}{l}\text { Home Falls and Accidents Screening tool (Mackenzie, } \\
\text { Byles, \& Higginbotham, 2002) }\end{array}$ & $\begin{array}{l}\text { BSFC (Burden Scale for Family Caregivers) } \\
\text { (Graessel, Berth, Lichte, \& Grau, 2014). }\end{array}$ \\
\hline
\end{tabular}


A Dutch instrument called "ZelfredzaamheidRadar" (LOCOmotion \& Knibbe \& Knibbe, 2015)

A Dutch instrument called "Zelfredzaamheidsmeter" (van de Schoot, 2013)

Elements of the EDOMAH assessment (Graff et al., 2007) (a community-based occupational therapy program)

Self-developed checklists of the organizations for which the participants worked
Safety Assessment of Function and the Environment for Rehabilitation (SAFER) tool (Oliver, Blathwayt, Brackley, \& Tamaki, 1993)

Dutch checklists, developed in part by the organizations for which the participants worked.

\section{References}

Alzheimer Nederland (2017). Cijfers en feiten over dementie. https://www.alzheimernederland.nl/sites/default/files/directupload/factsheet-dementie-algemeen.pdf, Accessed date: 4 August 2017

Alzheimer Nederland, \& Vilans (2013). Zorgstandaard Dementie. Amersfoort: Alzheimer Nederland \& Vilans.

Boots, L. M., de Vugt, M. E., van Knippenberg, R. J., Kempen, G. I., \& Verhey, F. R. (2014). A systematic review of Internet-based supportive interventions for caregivers of patients with dementia. International Journal of Geriatric Psychiatry, 29(4), 331-344. http://dx.doi.org/10.1002/gps.4016.

Case Management Society UK (2017). What is case management? https://www.cmsuk. org/case-management/what-is-case-management, Accessed date: 9 June 2017.

Central Committee on Research Involving Human Subjects Your research: Does it fall under them WMO. http://www.ccmo.nl/en/your-research-does-it-fall-under-thewmo, Accessed date: 19 September 2017

Centre of Expertise for Innovative Care and Technology (2015). Over EIZT/ZTL. http:// www.innovatiesindezorg.eu/over/over-eizt-ztl/, Accessed date: 17 July 2015.

de Bont, M., van Haaren, E., Rosendal, H., \& Wijboldus, M. (2012). Expertisegebied wijk verpleegkundige. Utrecht: Verpleegkundigen \& Verzorgenden Nederland.

de Haan, R., Limburg, M., Schuling, J., Broeshart, J., Jonkers, L., \& van Zuylen, P. (1993). Klinimetrische evaluatie van de Barthel Index, een maat voor beperkingen in het dagelijks functioneren. Nederlandse Tijdschrift voor Geneeskunde, 137(18), 917-921.

de Poulin, C. L., Gelinas, I., Gauthier, S., Dayton, D., Liu, L., Rossignol, M., ... Dastoor, D. (2006). Reliability and validity of the Safety Assessment Scale for people with dementia living at home. Canadian Journal of Occupational Therapy, 73(2), 67-75. http://dx.doi.org/10.1177/000841740607300201.

de Putter, I. D., Francke, A. L., de Veer, A. J. E., \& Rademakers, J. J. D. J. M. (2014). Kennissynthese de wijkverpleegkundige van vandaag en morgen: Rollen, samenwerking en deskundigheid van wijkverpleegkundigen. Utrecht: NIVEL.

Dunn Lopez, K., Gephart, S. M., Raszewski, R., Sousa, V., Shehorn, L. E., \& Abraham, J. (2017). Integrative review of clinical decision support for registered nurses in acute care settings. Journal of the American Medical Informatics Association, 24(2), 441-450. http://dx.doi.org/10.1093/jamia/ocw084.

Eaker, E. D., Vierkant, R. A., \& Mickel, S. F. (2002). Predictors of nursing home admission and/or death in incident Alzheimer's disease and other dementia cases compared to controls: A population-based study. Journal of Clinical Epidemiology, 55(5), 462-468. http://dx.doi.org/10.1016/S0895-4356(01)00498-X.

Fassaert, T., Lauriks, S., van de Weerd, S., Theunissen, J., Kikkert, M., Dekker, J., ... de Wit, M. (2014). Psychometric properties of the Dutch version of the self-sufficiency matrix (SSM-D). Community Mental Health Journal, 50(5), 583-590. http://dx.doi. org/10.1007/s10597-013-9683-6.

Fisher, G. S., Baker, A., Koval, D., Lishok, C., \& Maisto, E. (2007). A field test of the Cougar Home Safety Assessment (version 2.0) in the homes of older persons living alone. Australian Occupational Therapy Journal, 54(2), 124-130. http://dx.doi.org/10. 1111/j.1440-1630.2006.00604.x.

Gibson, G., Newton, L., Pritchard, G., Finch, T., Brittain, K., \& Robinson, L. (2014). The provision of assistive technology products and services for people with dementia in the United Kingdom. Dementia, 5(4), 681-701. http://dx.doi.org/10.1177/ 1471301214532643.

Giebel, C. M., Challis, D., \& Montaldi, D. (2015). Understanding the cognitive underpinnings of functional impairments in early dementia: A review. Aging \& Mental Health, 19(10), 859-875. http://dx.doi.org/10.1080/13607863.2014.1003282.

Gitlin, L. N., Schinfeld, S., Winter, L., Corcoran, M., Boyce, A. A., \& Hauck, W. (2002) Evaluating home environments of persons with dementia: Interrater reliability and validity of the Home Environmental Assessment Protocol (HEAP). Disability and Rehabilitation, 24(1-3), 59-71.

Graessel, E., Berth, H., Lichte, T., \& Grau, H. (2014). Subjective caregiver burden: validity of the 10-item short version of the Burden Scale for Family Caregivers BSFC-s. BMC Geriatrics, 14(1), 23. http://dx.doi.org/10.1186/1471-2318-14-23.

Graff, M. J., Vernooij-Dassen, M. J., Thijssen, M., Dekker, J., Hoefnagels, W. H., \& Olderikkert, M. G. (2007). Effects of community occupational therapy on quality of life, mood, and health status in dementia patients and their caregivers: a randomized controlled trial. Journals of Gerontology Series A: Biological Sciences and Medical Sciences, 62(9), 1002-1009. http://dx.doi.org/10.1093/gerona/62.9.1002.

Grol, R., \& Wensing, M. (2013). Characteristics of successful innovations. In R. Grol, M.
Wensing, M. Eccles, \& D. Davis (Eds.). Improving Patient Care (pp. 77-90). Oxford, UK: John Wiley \& Sons, Ltd.

Gulliksen, J., Göransson, B., Boivie, I., Blomkvist, S., Persson, J., \& Cajander, Å. (2003). Key principles for user-centred systems design. Behaviour \& Information Technology, 22(6), 397-409. http://dx.doi.org/10.1080/01449290310001624329.

Hulp bij Dementie (2016). Hulp bij Dementie. http://www.hulpbijdementie.nl/, Accessed date: January 2016.

Jaspers, M. W. (2009). A comparison of usability methods for testing interactive health technologies: Methodological aspects and empirical evidence. International Journal of Medical Informatics, 78(5), 340-353. http://dx.doi.org/10.1016/j.ijmedinf.2008.10. 002.

Katz, S., Ford, A. B., Moskowitz, R. W., Jackson, B. A., \& Jaffe, M. W. (1963). Studies of illness in the aged. The Index of ADL: A Standardized measure of biological and psychological function. Journal of the American Medical Association, 185, 914-919. http://dx.doi.org/10.1001/jama.1963.03060120024016.

Kawamoto, K., Houlihan, C. A., Balas, E. A., \& Lobach, D. F. (2005). Improving clinical practice using clinical decision support systems: a systematic review of trials to identify features critical to success. British Medical Journal, 330(7494), 765. http:// dx.doi.org/10.1136/bmj.38398.500764.8F.

Kempen, G. I., \& Suurmeijer, T. P. (1990). The development of a hierarchical polychotomous ADL-IADL scale for noninstitutionalized elders. The Gerontologist, 30(4), 497-502. http://dx.doi.org/10.1093/geront/30.4.497.

Kroneman, M., Boerma, W., van den Berg, M., Groenewegen, P., de Jong, J., \& van Ginneken, E. (2016). The Netherlands: health system review. Health Systems in Transition, 18(2), 1-239. http://www.euro.who.int/_data/assets/pdf_file/0016/ 314404/HIT_Netherlands.pdf.

Lach, H. W., Reed, A. T., Smith, L. J., \& Carr, D. B. (1995). Alzheimer's disease: Assessing safety problems in the home: While many caregivers are practicing some form of safety precautions, they may not be aware of all of their options or the best way to prevent accidents. Geriatric Nursing, 16(4), 160-164. http://dx.doi.org/10.1016/ S0197-4572(05)80022-9.

Lawton, M. P., \& Brody, E. M. (1969). Assessment of older people: Self-maintaining and instrumental activities of daily living. The Gerontologist, 9(3), 179-186. http://dx.doi. org/10.1093/geront/9.3_Part_1.179.

Lewis, J. R. (1995). IBM computer usability satisfaction questionnaires: Psychometric evaluation and instructions for use. International Journal of Human Computer Interaction, 7(1), 57-78. http://dx.doi.org/10.1080/10447319509526110.

Lewis, J. R. (2014). Usability: Lessons learned ... and yet to be learned. International Journal of Human Computer Interaction, 30(9), 663-684. http://dx.doi.org/10.1080/ 10447318.2014.930311.

LOCOmotion, \& Knibbe \& Knibbe (2015). ZelfredzaamheidsRadar. http://www zelfredzaamheidsradar.nl/, Accessed date: October 2015.

Maarse, J. A. M., \& Jeurissen, P. P. (2016). The policy and politics of the 2015 long-term care reform in the Netherlands. Health Policy, 120(3), 241-245. http://dx.doi.org/10. 1016/j.healthpol.2016.01.014.

Mackenzie, L., Byles, J., \& Higginbotham, N. (2002). Reliability of the Home Falls and Accidents Screening Tool (HOME FAST) for identifying older people at increased risk of falls. Disability and Rehabilitation, 24(5), 266-274. http://dx.doi.org/10.1080/ 09638280110087089.

MacNeil Vroomen, J., Bosmans, J. E., van de Ven, P. M., Joling, K. J., van Mierlo, L. D., Meiland, F. J., ... de Rooij, S. E. (2015). Community-dwelling patients with dementia and their informal caregivers with and without case management: 2-year outcomes of a pragmatic trial. Journal of the American Medical Directors Association, 16(9), 800.e801-800.e808. http://dx.doi.org/10.1016/j.jamda.2015.06.011.

MacNeil Vroomen, J., Van Mierlo, L. D., van de Ven, P. M., Bosmans, J. E., van den Dungen, P., Meiland, F. J. M., ... van Hout, H. P. J. (2012). Comparing Dutch case management care models for people with dementia and their caregivers: The design of the COMPAS study. BMC Health Services Research, 12(1), 132. http://dx.doi.org/ 10.1186/1472-6963-12-132.

Moïse, P., Schwarzinger, M., \& Um, M. (2004). Dementia care in 9 OECD countries. Paris: OECD Publishing.

Nielsen, J. (1994). Heuristic evaluation. In J. Nielsen, \& R. L. Mack (Eds.). Usability inspection methods (pp. 25-62). New York: John Wiley \& Sons.

Nijboer, C., Triemstra, M., Tempelaar, R., Sanderman, R., \& van den Bos, G. A. (1999). Measuring both negative and positive reactions to giving care to cancer patients: Psychometric qualities of the Caregiver Reaction Assessment (CRA). Social Science \& Medicine, 48(9), 1259-1269. http://dx.doi.org/10.1016/S0277-9536(98)00426-2. 
Oliver, R., Blathwayt, J., Brackley, C., \& Tamaki, T. (1993). Development of the Safety Assessment of Function and the Environment for Rehabilitation (SAFER) tool Canadian Journal of Occupational Therapy, 60(2), 78-82. http://dx.doi.org/10.1177/ 000841749306000204.

Pot, A. M., Deeg, D. J., van Dyck, R., \& Jonker, C. (1998). Psychological distress of caregivers: The mediator effect of caregiving appraisal. Patient Education and Counseling, 34(1), 43-51. http://dx.doi.org/10.1016/S0738-3991(98)00048-2.

Prince, M., Prina, M., \& Guerchet, M. (2013). World Alzheimer Report 2013. Journey of caring. An analysis of long-term care for dementia. London, UK: Alzheimer's Disease International. https://www.alz.co.uk/research/WorldAlzheimerReport2013.pdf.

Risco, E., Cabrera, E., Jolley, D., Stephan, A., Karlsson, S., Verbeek, H., ... Zabalegui, A. (2015). The association between physical dependency and the presence of neuropsychiatric symptoms, with the admission of people with dementia to a long-term care institution: a prospective observational cohort study. International Journal of Nursing Studies, 52(5), 980-987. http://dx.doi.org/10.1016/j.ijnurstu.2015.02.013.

Robinson, B. C. (1983). Validation of a Caregiver Strain Index. Journal of Gerontology, 38(3), 344-348. http://dx.doi.org/10.1093/geronj/38.3.344.

Schols, J. M., \& van der Schriek-van Meel, C. (2006). Day care for demented elderly in a dairy farm setting: Positive first impressions. Journal of the American Medical Directors Association, 7(7), 456-459. http://dx.doi.org/10.1016/j.jamda.2006.05.011.

Shah, S. G. S., Robinson, I., \& AlShawi, S. (2009). Developing medical device technologies from users' perspectives: A theoretical framework for involving users in the development process. International Journal of Technology Assessment in Health Care, 25(04), 514-521. http://dx.doi.org/10.1017/S0266462309990328.

Thoma-Lürken, T., Bleijlevens, M. H., Lexis, M. A., Hamers, J. P., \& de Witte, L. P. (2015). An overview of potential labor-saving and quality-improving innovations in longterm care for older people. Journal of the American Medical Directors Association, 16(6), 482-489. http://dx.doi.org/10.1016/j.jamda.2014.12.017.

Thoma-Lürken, T., Bleijlevens, M. H. C., Lexis, M. A. S., de Witte, L. P., \& Hamers, J. P. H. (2018). Facilitating aging in place: A qualitative study of practical problems preventing people with dementia from living at home. Geriatric Nursing, 39(1), 29-38. http://dx.doi.org/10.1016/j.gerinurse.2017.05.003.

Thompson, C., Aitken, L., Doran, D., \& Dowding, D. (2013). An agenda for clinical decision making and judgement in nursing research and education. International Journal of Nursing Studies, 50(12), 1720-1726. http://dx.doi.org/10.1016/j.ijnurstu.2013.05. 003.

van de Schoot, R. (2013). Zelfredzaamheidsmeter. De zelfredzaamheidsmeter is een handig gespreksinstrument om per levensgebied de zelfredzaamheid van een cliënt te bepalen. http://www.vilans.nl/publicatie-zelfredzaamheidsmeter.html, Accessed date: 10 February 2015.

van der Roest, H. G., Meiland, F. J., Comijs, H. C., Derksen, E., Jansen, A. P., van Hout, H. P., ... Droes, R. M. (2009). What do community-dwelling people with dementia need? A survey of those who are known to care and welfare services. International Psychogeriatrics, 21(5), 949-965. http://dx.doi.org/10.1017/s1041610209990147.

van der Weegen, S., Verwey, R., Tange, H. J., Spreeuwenberg, M. D., \& de Witte, L. P. (2014). Usability testing of a monitoring and feedback tool to stimulate physical activity. Patient Preference and Adherence, 8, 311-322. http://dx.doi.org/10.2147/ PPA.S57961.

Verbeek, H., Zwakhalen, S. M., Schols, J. M., \& Hamers, J. P. (2013). Keys to successfully embedding scientific research in nursing homes: A win-win perspective. Journal of the American Medical Directors Association, 14(12), 855-857. http://dx.doi.org/10.1016/ j.jamda.2013.09.006.

von Kutzleben, M., Schmid, W., Halek, M., Holle, B., \& Bartholomeyczik, S. (2012). Community-dwelling persons with dementia: What do they need? What do they demand? What do they do? A systematic review on the subjective experiences of persons with dementia. Aging \& Mental Health, 16(3), 378-390. http://dx.doi.org/10. 1080/13607863.2011.614594.

Wolfs, C. A., de Vugt, M. E., Verkaaik, M., Verkade, P. J., \& Verhey, F. R. (2010) Empowered or overpowered? Service use, needs, wants and demands in elderly patients with cognitive impairments. International Journal of Geriatric Psychiatry, 25(10), 1006-1012. http://dx.doi.org/10.1002/gps.2451.

World Health Organization, \& Alzheimer's Disease International (2012). Dementia: A public health priority. Geneva: World Health Organization. http://www.who.int/ mental health/publications/dementia report 2012/en/.

Zarit, S. H., Reever, K. E., \& Bach-Peterson, J. (1980). Relatives of the impaired elderly: correlates of feelings of burden. The Gerontologist, 20(6), 649-655. http://dx.doi.org/ 10.1093/geront/20.6.649. 